Article

\title{
Software-Defined Mobile Supply Chains: Rebalancing Resilience and Efficiency in Production Systems
}

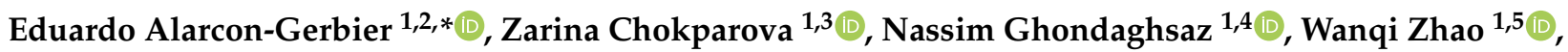 \\ Hani Shahmoradi-Moghadam ${ }^{1,6} \mathbb{D}^{\mathbb{D}}$, Uwe Aßmann ${ }^{5} \mathbb{D}$ and Orçun Oruç 5
}

1 Boysen-TU Dresden Research Training Group, Technische Universität Dresden, 01187 Dresden, Germany; zarina.chokparova@tu-dresden.de (Z.C.); nassim.ghondaghsaz@tu-dresden.de (N.G.); wanqi.zhao@tu-dresden.de (W.Z.); hani.shahmoradi@tu-dresden.de (H.S.-M.)

2 Business Administration, esp. Industrial Management, Technische Universität Dresden, 01069 Dresden, Germany

3 Process Control Systems and Process Systems Engineering Group, Technische Universität Dresden, 01069 Dresden, Germany

4 Institute of Media and Communication Science, Technische Universität Dresden, 01069 Dresden, Germany

5 Software Technology, Institute for Software and Multimedia Technology, Technische Universität Dresden, 01069 Dresden, Germany; uwe.assmann@tu-dresden.de (U.A.); orcun.oruc@tu-dresden.de (O.O.)

6 Transport Services and Logistics, Technische Universität Dresden, 01069 Dresden, Germany

* Correspondence: eduardo.alarcon@tu-dresden.de

\section{check for}

updates

Citation: Alarcon-Gerbier, E.;

Chokparova, Z.; Ghondaghsaz, N.;

Zhao, W.; Shahmoradi-Moghadam,

H.; Aßmann, U.; Oruç, O

Software-Defined Mobile Supply

Chains: Rebalancing Resilience and

Efficiency in Production Systems.

Sustainability 2022, 14, 2837. https://

doi.org/10.3390/su14052837

Academic Editor: Ripon Kumar

Chakrabortty

Received: 29 December 2021

Accepted: 22 February 2022

Published: 28 February 2022

Publisher's Note: MDPI stays neutral with regard to jurisdictional claims in published maps and institutional affiliations.

Copyright: (C) 2022 by the authors. Licensee MDPI, Basel, Switzerland. This article is an open access article distributed under the terms and conditions of the Creative Commons Attribution (CC BY) license (https:// creativecommons.org/licenses/by/ $4.0 /)$

\begin{abstract}
The miniaturization and modularization of production capacity brings with it not only greater agility and efficiency, but also increased flexibility in the form of mobility. This flexibility allows production capacity to be moved when and where it is most needed, generating new business opportunities, e.g., allowing modular units to be rented, leased, or shared. This flexibility, however, requires information and control systems that ensure a correct and secure flow of information between different stakeholders of the supply chain. Based on this, the present article characterizes the concept of software-defined mobile supply chains, presenting its main requirements, opportunities, and limitations. In addition, we present two case studies in which the proposed concept is evaluated in order to demonstrate its applicability. Here, due to the new optimization problems that arise when considering mobile facilities, special interest is given to the planning and control of the required operations, as well as the difficulties associated with the exchange of physical and intellectual assets between different stakeholders.
\end{abstract}

Keywords: adaptive manufacturing; flexible supply chain; mobile factory; movable production unit; shared factory

\section{Introduction}

Current volatile markets and customization demands call for a transition from the status quo of traditional supply chains to more dynamic and shorter-term supply networks [1] In addition, as much as technology decreases the role of low-cost labor and diminishes the effect of economies of scale, decentralized manufacturing systems are predicted to become the norm for production systems of the future [2]. These trends are already giving rise to smaller and more flexible factories located closer to the customers and shaping more responsive and environmentally friendly supply chains. For example, Schlemmer has developed a mobile factory inside containers that can produce up to 3000 different products and up to $62,000 \mathrm{~m}$ of corrugated tube per day [3]. Bionic Production $\mathrm{GmbH}$ has developed a modular factory inside a 20-foot container that enables a cost-efficient supply of metal and plastic parts. This factory is equipped with $3 \mathrm{D}$ printing equipment and is therefore capable of producing spare and functional parts on site in a short amount of time [4]. Pfizer has designed a modular manufacturing system for the development of oral solid dose pharmaceuticals with the aim of accelerating the speed of tablet production [5]. Unilever 
has developed a prototype called "nano factory" for the production of liquid bouillon, which is fully digitized and can, therefore, be programmed and controlled remotely. This mini factory is composed of a production line that fits completely into a 40-foot container [6]. Modular units have also been developed in the recycling sector. For example, there are scalable recycling units for waste oil [7], bulk waste [8], non-recyclable plastics [7], and woody biomass [9].

There are several technological innovations that support the flexibility of such production units, such as modularization, additive manufacturing, and advances in robotics. They enable, on the one hand, the simplification of production and, on the other hand, an increase in performance [10]. Here, modularization can be highlighted as the main driver since it increases production flexibility in different ways. First, by increasing the number of modules or establishing parallel lines, production capacity can be expanded [11-13]. Second, by exchanging certain processing modules, the mix of products that can be manufactured can be altered $[14,15]$. Finally, modularity also allows flexibility in terms of mobility, allowing production units to be moved to another location at short notice, bringing them closer to the feedstock source or to the customer's site [16-18].

The mobility of production units gives rise to mobile supply chains, in which production capacity can be relocated at low cost and in the short term. Here, new business opportunities can emerge as modular units can be leased or even shared between different members of the supply chain. This, however, is possible not only through the consideration of mobile production units, but also a secure interconnection and information flow must be ensured through the use of adequate information systems that are capable of detecting, processing, and sending information between the different actors or productive assets [19]. The inclusion of such control and information systems leads to what we call a SoftwareDefined Mobile Supply Chain (SD-MSC). This concept was difficult to implement in the past because production and communication facilities were not mobile or, when they were, did not provide sufficient production capabilities. In the past few years, following significant progress in multiple dimensions of technologies, such as 3D printing applications in the supply chain [20], blockchain for smart contracts [21], 5G impact on the industry [22], Internet of Things [23], and cyber-physical manufacturing systems [24], new opportunities for mobile, scalable, and modular production systems have appeared so a characterization of SD-MSC can be undertaken. Therefore, the purpose of this article is to analyze and discuss the requirements and effects of mobility on the supply chain. In this regard, we define the research questions as follows:

RQ1: How can an SD-MSC be defined and which business model emerges when moving production units between different members of the supply chain?

RQ2: What opportunities and requirements arise when considering SD-MSCs?

RQ3: What has to be considered when integrating, planning, and controlling SD-MSCs?

Based on these research questions, the contribution and novelty of the present paper can be summarized as follows:

1. This study expands the concepts associated with mobile manufacturing systems by considering the new opportunities brought about by the mobility of modular units within a supply chain. For example, the possibility of moving production capacity and its installation at the sites of partner companies, the option of sharing production assets, or leasing or renting modular units from external companies brings with them new opportunities and challenges that have not been adequately evaluated in the literature. Based on that, this article presents a characterization of the SD-MSC concept, describing its main characteristics and requirements.

2. We present two case studies which are under evaluation. The former focuses on the implementation of a recycling network using modular units and the latter covers the opportunity of asset sharing in the process industries sector.

3. We pay special attention to the challenges and requirements that arise when planning an SD-MSC. The use of mobile units entails the consideration of a short-term location 
problem, so it could be integrated into the tactical or operational planning. In addition, integrating multiple stakeholders increases the complexity due to the possible incongruence between the objectives of each participant.

4. Controlling an SD-MSC entails various challenges from the point of view of hardware and associated information systems. In addition, confidentiality and security of data transmission, as well as trust between the different partners, play an important role.

The overall outline of the paper is as follows. A literature review is presented in Section 2 and the SD-MSC concept is introduced in Section 3. Section 4 discusses its requirements, opportunities, and challenges and Section 5 provides managerial insights. We conclude the paper with a short summary in Section 6.

\section{Literature Review}

In this section, we review the literature that analyzes and discusses concepts related to decentralized production, mobile manufacturing systems, and mobile production. To find related concepts, we focused on search keywords such as: "mobility", "modular facility", "shared facility", "decentralized production", and "mobile supply chain".

The first related concept is known as distributed manufacturing systems (DMSs), which has been addressed by several authors. Mourtzis and Doukas [25] discussed the main trends and challenges related to DMS, presenting also a comparison with other production paradigms. Mourtzis et al. [26] evaluated the performance and feasibility of centralized and distributed manufacturing networks under a high level of customization, concluding that a DMS achieves higher productivity and flexibility compared to centralized networks. Srai et al. [27] described the evolution of DMS and presented new opportunities that arise from integrating technological developments, such as 3D printing, continuous production processes, and digitization. Rauch et al. [28] approached the DMS concept with a focus on emerging markets and sustainable production. They identified several reasons that encourage the implementation of DMS, subsequently analyzing this concept based on four dimensions of sustainability: economic, ecological, social, and institutional. In addition, Barni et al. [29] and Reichwald et al. [30] addressed decentralized production networks composed of modular mini-factories.

A higher degree of flexibility is not only achieved through decentralized production networks, but also by considering production systems that can adjust their architecture and resources on demand and efficiently. In this context, the concept of reconfigurable manufacturing systems (RMSs) has been introduced, which includes a range of progressively developed hardware and software technologies, such as sensors, robots, advanced ERP systems, and data analytics. Mehrabi et al. [31] defined this concept and presented its key features, including the modularity of production units. Similarly, ElMaraghy [32] compared the flexibility and reconfigurability of production systems, presenting also an overview of the prerequisites for RMS. Bi et al. [33] presented strategies to meet RMS requirements and discussed critical issues related to their design and control. In contrast to previous articles, Koren et al. [34] formulated the operational principles for RMSs and provided a literature review based on these, discussing the role of intelligent manufacturing technologies as well.

As mentioned in the previous paragraphs, higher levels of flexibility are achieved through the decentralization and reconfiguration of production systems. However, miniaturization and modularization also support mobility. Here, the term mobility is defined as geographical flexibility, meaning that production modules can be relocated between different sites easily and at short notice [35]. This requires that the production units be portable, meaning that all equipment necessary for production can be dismantled, loaded, transported, and reinstalled in its new position in the shortest possible time. In this context, mobile manufacturing systems (MMS) consisting of production modules have been studied and developed, which can also be combined and reconfigured for the assembly of new products as well as be scaled to reach new volumes. This concept was discussed by Lier et al. [36], who presented an overview of the related literature and the opportunities and risks that this new flexibility feature brings. In addition, this concept was investi- 
gated within the research project called "Factory-in-a-Box" (FiaB), in which configurable production modules are located in containers, enabling the companies to provide highly customized products at a location of their choice [37]. Similarly, the concept of LocationIndependent Manufacturing (LIM) was introduced by Peltokoski et al. [38] as a possible future manufacturing system in which production units can be moved to locations close to customers. In this way, transport costs can be reduced, as only a mini-factory needs to be moved and not several finished products. This concept is closely related to FiaB. However, the main difference is that LIM focuses primarily on investigating realistic business operation possibilities, whilst the concept of FiaB examines more technical aspects [38]. Mobile manufacturing systems were also addressed by Fox $[39,40]$, who discussed the extent to which MMS can increase location diversity, decentralizing production in a more ecological and social manner. The FiaB concept has also been formulated mathematically. Jiang et al. [41] developed a mathematical model for the joint planning of subassembly modules and network design, and Pasha et al. [42] addressed the problem of planning travel routes for modular units.

The main characteristics of the concepts described above are summarized in Table 1. They have conceptualized a transition from centralized production to geographically distributed, adaptable, and mobile production approaches. However, the effects of mobility on the supply chain have seen little discussion. A mobile supply chain brings with it new opportunities, since production systems can be adapted not only internally, but also through modular units of other stakeholders. In other words, the decentralization and reconfiguration of production systems can be complemented by including new modular units that can be rented or leased temporarily, as well as by the installation of modular units at partner company locations.

Table 1. Similarities and differences with related concepts.

\begin{tabular}{|c|c|c|c|c|c|c|c|c|c|c|}
\hline Author(s) & 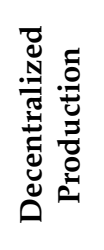 & 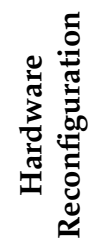 & 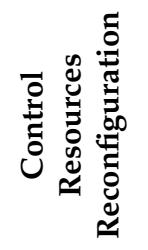 & 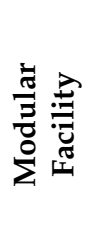 & 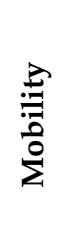 & 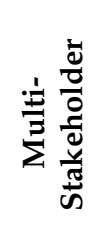 & 总: & 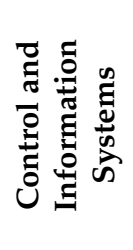 & 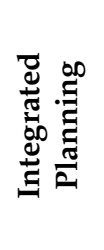 & 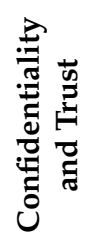 \\
\hline Adamietz et al. [43] & $\checkmark$ & $\checkmark$ & $\checkmark$ & $\checkmark$ & $\checkmark$ & & & $\checkmark$ & & \\
\hline Alix et al. [44] & $\checkmark$ & $\checkmark$ & $\checkmark$ & $\checkmark$ & $\checkmark$ & & & & & \\
\hline Barni et al. [29] & $\checkmark$ & & & $\checkmark$ & & & & $\checkmark$ & & \\
\hline Bi et al. [33] & & $\checkmark$ & $\checkmark$ & $\checkmark$ & & & & & & \\
\hline ElMaraghy [32] & & $\checkmark$ & $\checkmark$ & $\checkmark$ & & & & & & \\
\hline Fox $[39,40]$ & $\checkmark$ & & & $\checkmark$ & $\checkmark$ & & & & & \\
\hline Jackson et al. [37] & $\checkmark$ & $\checkmark$ & & $\checkmark$ & $\checkmark$ & $\checkmark$ & $\checkmark$ & & & \\
\hline Jiang et al. [41] & $\checkmark$ & & & $\checkmark$ & $\checkmark$ & $\checkmark$ & & & $\checkmark$ & \\
\hline Koren et al. [34] & & $\checkmark$ & $\checkmark$ & $\checkmark$ & & & & & & \\
\hline Lier et al. [36] & $\checkmark$ & $\checkmark$ & $\checkmark$ & $\checkmark$ & $\checkmark$ & & & & & \\
\hline Mehrabi et al. [31] & & $\checkmark$ & $\checkmark$ & $\checkmark$ & & & & & & \\
\hline Mourtzis and Doukas [25] & $\checkmark$ & & & & & & & & & \\
\hline Mourtzis et al. [26] & $\checkmark$ & & & & & & & & & \\
\hline Pasha et al. [42] & $\checkmark$ & & & $\checkmark$ & $\checkmark$ & $\checkmark$ & & & $\checkmark$ & \\
\hline Peltokoski et al. [38] & $\checkmark$ & & & $\checkmark$ & $\checkmark$ & & & $\checkmark$ & & \\
\hline Rauch et al. $[1,45]$ & $\checkmark$ & $\checkmark$ & & $\checkmark$ & $\checkmark$ & & & & & \\
\hline Rauch et al. [46] & $\checkmark$ & $\checkmark$ & & $\checkmark$ & $\checkmark$ & $\checkmark$ & $\checkmark$ & & & \\
\hline Rauch et al. [28] & $\checkmark$ & & & & & & & & & \\
\hline Reichwald et al. [30] & $\checkmark$ & & & $\checkmark$ & & & & & & \\
\hline Srai et al. [27] & $\checkmark$ & & & & & & & & & \\
\hline Stillström and Jackson [35] & $\checkmark$ & $\checkmark$ & & $\checkmark$ & $\checkmark$ & $\checkmark$ & $\checkmark$ & & & \\
\hline This study & $\checkmark$ & $\checkmark$ & $\checkmark$ & $\checkmark$ & $\checkmark$ & $\checkmark$ & $\checkmark$ & $\checkmark$ & $\checkmark$ & $\checkmark$ \\
\hline
\end{tabular}


As presented in this section, several articles have introduced concepts related to mobile and modular production systems, mostly from a company's internal point of view. However, several stakeholders interact in a supply chain, and they may have different objectives or interests. The inclusion of this multiplicity makes it interesting to analyze the benefits, requirements, and opportunities that arise with the option of moving, sharing, or renting production capacity in the form of modular units between different supply chain members.

\section{Research Concept}

A Mobile Supply Chain (MSC) is composed of reconfigurable manufacturing systems distributed over several locations. A factory is either stationary, i.e., located at a fixed location, or mobile, in which case the locations of production units can be changed. A stationary factory consists of production lines with a fixed line of stations. In contrast, a mobile factory is composed of reconfigurable production lines which can be adapted according to new production plans, involving an internal mobility of stations and an external relocation of the entire production line. The latter is supported by means of, for example, placing mobile manufacturing units inside transportable containers. As shown in Figure 1, reconfigurable production lines, and by default, mobile factories, can be easily adjusted, shipped to the location of a customer or supplier, and put together to build a temporary facility. Following a distributed manufacturing approach, several facilities are owned by a network of companies, representing a production and distribution network, in which also several distributed suppliers and customers are involved. This network includes multiple stakeholders, which are represented graphically in Figure 1 through the nodes, and entails high flows of information and materials, making the decision-making process complex. Including mobility within the network further increases the complexity of decision making, since the problems of location and reconfiguration of mobile facilities arise. In contrast to classic DMS and MMS, which are concepts for in-house production, MSCs can be seen as multi-stakeholder supply chains with one or several MMS.

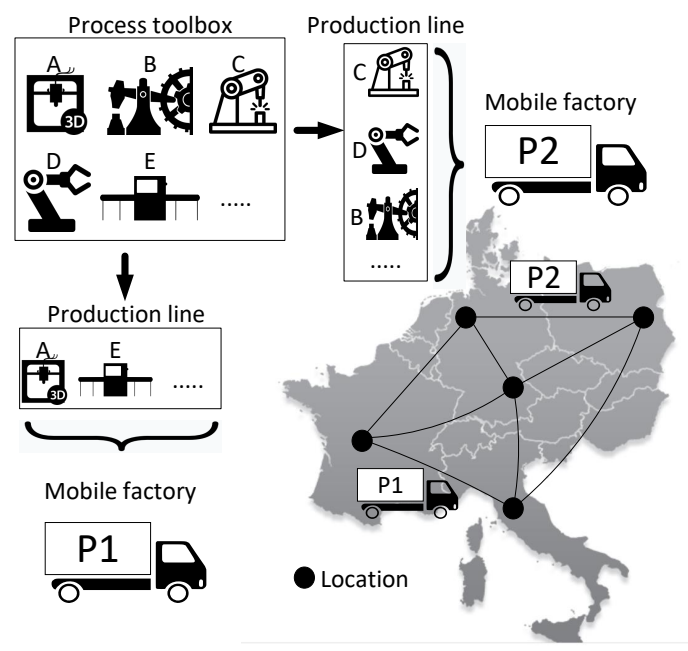

Figure 1. A mobile supply chain.

The correct operation and implementation of an MSC requires not only the inclusion and development of different technologies, but a correct interconnection and information flow must also be ensured through the use of appropriate information systems which are able to detect, process, and send information between different stakeholders or production assets [19]. On this basis, we define an SD-MSC as a mobile supply chain in which all reconfigurations of the logistic network, i.e., all movements of mobile production units, are under software control. (Note: the term MSC can be found in the literature, but with a different definition; Eng [47] presented the idea of MSC management but related this to 
the inclusion of mobile and/or wireless technology in the supply chain; by contrast, our concept mobility is associated with equipment and facilities).

As mentioned above, the possibility of moving production capacity brings with it new business opportunities. Here, two business models can be defined depending on who provides and offers the required service:

\subsection{Infrastructure-as-a-Service}

This business model is associated with the installation of modular units for decentralized production. For example, a company can install its production modules directly at the customer's site to achieve higher degrees of customization or reduce transportation costs. These modules can be operated directly by the customer, but they belong to the parent company. In addition, a company can install its production modules directly at the suppliers' site to improve quality, complement certain processes, or reduce unnecessary transportation. Finally, the modular units can be installed in third party locations, i.e., external companies can provide the service of leasing the facilities, power supply, waste disposal, and services required for the proper operation of the modular units.

This business opportunity is associated with the following case study: Company A generates a large amount of waste oil through its production processes. The disposal of this waste is tightly controlled because of the level of contamination that could be caused if it were to be carelessly released into the environment. Here, external companies are engaged in its collection. On the one hand, companies that generate a low volume of waste oil must pay a variable fee for this. On the other hand, companies that need to dispose large quantities can make a profit, since the collection companies pay on the basis of the volume collected. Thus, Company A generates some revenue from this. In the past few years, modular units capable of decentralized waste recycling have been developed, which presents some opportunities compared to centralized recycling. For example, a modular unit was developed which can process up to $2500 \mathrm{~L}$ of waste oil per day with a conversion rate of $0.9 \mathrm{~L}$ of recycled oil per every liter of waste oil. The purchase price of such equipment, however, is a relevant factor in the investment decision. In addition, a high utilization rate of the equipment must be ensured in order to justify the investment. Therefore, Company A is planning to organize a recycling network. To do this, Company A wants to plan the movement of waste between its production and distribution centers and its subsequent treatment in a decentralized manner. Some of Company A's suppliers and associated companies are also interested in this business because they can also expect benefits, such as lower costs paid for disposal or the direct obtaining of recycled oil that can be returned to the production cycle. In addition, these interested companies contribute not only with their waste but also with their locations. Here, the benefit of moving mobile recycling units (MRUs) instead of moving waste should be compared. This case study is further discussed in Section 4.3.2.

\subsection{Module-as-a-Service}

This is associated with the commercialization of modular production units. Companies without production capacity may lease modular units for the manufacture of new products, thereby avoiding high investment costs in new equipment or production outsourcing. For example, a pharmaceutical production company could rent modular capacity for the production of small quantities of new drugs required for clinical trials or for rare diseases, which would be prohibitively expensive to produce in large-scale facilities [48]. In the construction sector, a contractor could temporally rent configured mobile facilities from a specialized network partner for just-in-time production [45]. In addition, companies in volatile markets may choose to lease modular units to cope with production peaks that may arise that exceed the company's production capacity. The aforementioned cases focus on leasing modular units to address the lack of production capacity. However, the shared investment of modular units by several companies is also conceivable. On the basis of agreements and contracts, the shared use of extra production capacity can be defined. This 
case, however, may require higher levels of trust between the parties to the agreement due to insecurity or lack of guarantees in the shared use of equipment.

The case study being analyzed can be described as follows: Company P owns modular production units installed in movable containers, which can be easily transported by truck. Due to the low utilization of such equipment, this expensive and highly automated equipment is not needed continuously at Company P's production site. Therefore, it can be shared with its direct customers. First, Company P decreases its fixed costs by sharing an expensive asset. Second, it achieves increased flexibility and a higher degree of customization through local and decentralized production. Finally, product lead-time can be reduced in the event of a change in specifications by just adjusting the settings of the mobile units. Company $\mathrm{O}$ is the asset operator that uses this equipment in their manufacturing or process. This company receives a module unit from the asset supplier (Company $\mathrm{P}$ ) and merges it into their production process for intermediate production and process efficiency enhancement. This case study is further discussed in Section 4.4.1.

\section{Discussion}

In this section, we present the main results of our analysis, discussing the main opportunities, requirements, and challenges for the operation and control of SD-MSCs.

\subsection{Opportunities through SD-MSC}

On the basis of the definitions presented in Section 3, the following reasons can be contended for the implementation of an SD-MSC (note that the same reasons associated with the concepts of DMS and MMS can be listed in this section, such as mass customization and the promotion of regional and sustainable production, which have been discussed extensively by Rauch et al. [28] and Fox [40]):

1. Fulfilling customer demand under uncontrolled conditions: Unpredictable peaks in demand sometimes happen and the deployment of mobile facilities could help managers to meet that increase. Moreover, when unpredictable incidents occur, they may disturb production processes and the proper functioning of the supply chain. In such a case, mobile production facilities can be introduced as a temporary solution.

2. Operational flexibility: Instead of purchasing and maintaining an expensive machine, in many cases companies can rent it for the period of time they need it. In addition, if a company owns an expensive machine with a low utilization rate, it could be shared between similar factories and relocated as needed.

3. Optimization of supply chains with high logistic costs: In a supply chain where the different components and raw materials are far away from each other and have high transport costs, the use of an SD-MSC may reduce unnecessary transports since the parts of the products can be manufactured locally, requiring mainly a correct transmission of data, a dynamic management of possible productive resources, and a strong trust between partners.

4. Provision of maintenance services at the customer's location: Instead of moving large machines or assets, which in some cases involves spending large amounts of money and time to send a broken asset elsewhere for maintenance purposes, all services could be provided at the facilities of the customer, often resulting in a cheaper and faster return to operational status.

\subsection{Requirements for $S D-M S C$}

In order to implement the SD-MSC concept efficiently, some different aspects should be taken into account:

1. Partner collaboration: Strategic partnership in supply chains has always been of importance due to the complexity of material and information flow. The design, materials, and components can come from different countries (partners), making the controlling process more complex [38]. In fact, in an SD-MSC, as the movable factory changes its locations, various internal (focal firm) and external (local) partners become 
involved. This may introduce challenges for the communication and information flows which are necessary for effective integration. A key component for improving information exchange and communication between multiple stakeholders is building trust and commitment among them $[49,50]$. With a high level of supply chain trust, partners will be able to establish an efficient collaboration and thereby increase the value-adding of any SD-MSC. Several factors can affect partners' trustworthiness, categorized into four groups: governance, transaction costs, information, and social exchange. For instance, when considering the social aspect, if the company decides to use part-time local employees, they should apply some measures to build trust and loyalty in those employees to improve the chance of seeing efficient performance [51].

2. Regulatory requirements: The main advantage of mobile units is the ability to install production capacity where it is needed, for example at a customer's or a supplier's site. One important aspect of this location changing is the difference of regulations and laws in each location. Legal permits should be considered, since each country has different legislative and taxation regulations. Sanitation permits should also be regarded in the case that emissions or waste are generated through production. Moreover, employee rights and labor regulations must be taken into account, for example the maximum number of hours that can be worked, mandatory health insurance, etc.

3. Socio-cultural aspects: These mobile facilities can operate far from the company's main site and require a skilled workforce to run them. The required capacities and number of personnel depend on the different production processes needed for the manufacturing, as well as the level of automation of the mobile unit. The essential skill is the maintenance of the processing machinery in the mobile facility. Depending on the case, one solution could involve sending a limited number of permanent workers with the mobile unit and hiring some employees locally [38]. However, finding qualified and skilled employees, perhaps for a short period of time, might be a complicated task.

4. Supply requirements: Managing the operations of an SD-MSC requires more complex activities than those necessary for the coordination of fixed facilities, since the location decision has a direct impact on other planning issues. An important factor to consider is the correct, safe, and timely supply of information and raw materials. The use of a Product Data Management system (PDM) and blockchain technology for information handling can be helpful for the easy transfer and storage of the information on production and products, allowing a quick information exchange between different production sites. In addition, the supply of raw material to the variable location of the mobile facility may require flexible agreements with suppliers. Here, smart contracts with suppliers could play an important role [21].

5. Technological requirements: The production process should be quickly and flexibly reconfigurable in order to allow it to be shipped and installed at a new position. Whether reconfiguration/assembly processes are planned by an automatic planning system or by human experts, there still remains the challenge to reach the planned goals under the occurrence of real-world exceptions. Such exceptions range from temporary execution errors to a collapse of the whole process. The assembly system must anticipate and predict potential exceptions and errors and regulate the assembly plans. In addition, the detailed documentation of processes and products, the modularization of subsystems, and an adaptive master production scheduling system are required. These demands could be addressed by their integration into an appropriate information system. In addition, since specialized personnel may be limited at the new locations, the control of the equipment and associated software must be as user-friendly as possible, accompanied by a high level of automation and remote assistance [43]. Furthermore, the software communication layer needs to be able to incorporate solutions aimed at the preservation of confidentiality of exchanged information and the support of secure computation services. Different protocols, including secure multiparty computation [52] and information sharing 
architectures based on homomorphic encryption [53], could be implemented to secure confidentiality of sensitive data.

\subsection{Planning an SD-MSC}

Figure 2 shows an adapted supply chain structure presenting the main decisions at each planning level [54]. Since technological advances are shaping a more flexible supply chain in which it is possible to relocate modular facilities at comparatively short notice, the assumption that production sites are immobile no longer applies. This seems interesting because, for mobile factories, the location decision no longer has to be made on a strategic level but is instead made on an operational/tactical level and can, therefore, be made together with the operational production and distribution planning.

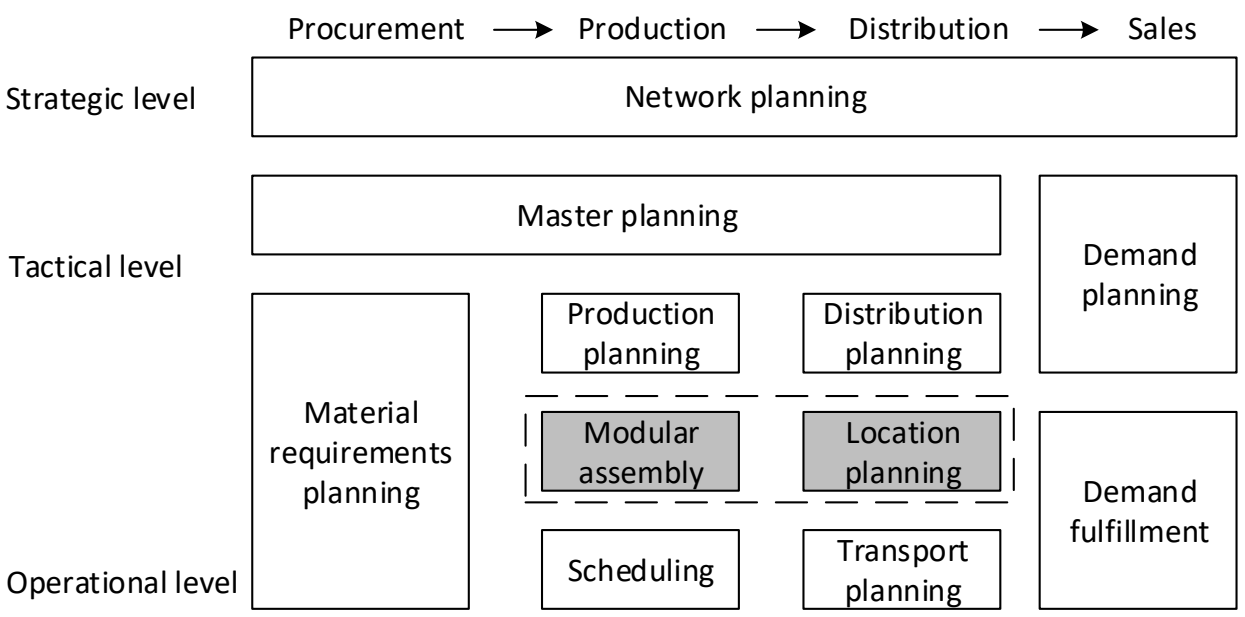

Figure 2. Adjusted supply chain management structure.

\subsubsection{Integrated Planning}

To achieve optimal coordination within an SD-MSC, it can be helpful to integrate models that involve both production and distribution decisions. Traditionally, these two tasks are planned separately in a sequential manner since both are complex problems in and of themselves. This, however, leads to sub-optimal results which could be improved through integrated planning. In addition, the consideration of mobile facilities within the integrated production and distribution planning makes it necessary to link them to the facility location problem. Therefore, three planning decisions play a significant role here:

1. Location planning: The first decision, on the location, refers to finding the best position for the facilities in order to optimize one or several objective functions, such as minimization of transportation costs, assignment cost, and/or costs associated with the opening or closing of facilities [55]. Since the facilities can be moved to another location at short notice, the relocation route/sequence must also be determined [56].

2. Production planning: The second decision is related to production, in which the aim is to find the best use of resources with the intention of satisfying production requirements and fulfilling customer orders. Here, capacity planning also plays an important role. Each mobile facility can be composed of different modules and its capacity depends on the type and quantity of modules [14]. The problem of module reassembly can also be considered, which is associated with the flexibility of the processes to be reorganized to form new production lines for the manufacture of different products [15].

3. Distribution planning: The last planning decision is about how to deliver the products to the customers. The classical problem is to find optimal delivery routes which fulfill customer demands by minimizing total costs, meeting vehicle capacity restrictions, or reducing delivery delays [57]. 
Many papers related to these three planning problems can be found in the literature, as well as some combinations of the three, such as the location-routing problem [58] or the integrated planning of production and distribution [59]. However, there are just a few papers that solve these three planning decisions simultaneously since, due to the strategic nature of the location decision, the production sites are usually assumed as fixed, which hinders an altering of the location in the short term [60]. These problems can be represented by mathematical models and solved with the help of mathematical programming and heuristics to find (near) optimal solutions. Nevertheless, the simultaneous planning of production, distribution, and choosing facility location is a complex problem that can be solved with the help of exact solution methods with short computational times, but only for small-sized problems. This is due to the combination of three complex problems in the same case [61]. In order to solve bigger instances, new algorithms should be developed that help solve this novel type of simultaneous planning.

\subsubsection{Case Study: Planning of a Mobile Recycling Network}

In this section, we present results associated with the planning of the case study described in Section 3.1. Since waste oil can be categorized as a hazardous waste, its transportation is a relevant issue. In addition, due to the modularity of the considered recycling units, they can be transported from one site to another easily and at low cost. On this basis, it may be better, from an economic and ecological point of view, to relocate the mobile units between different sites at short notice in order to reduce the unnecessary transportation of hazardous waste.

The planning of the recycling network under study involves the integration of the three subproblems described in Section 4.3.1. First, a multi-period location problem must be solved. Here, it must be decided where to install the mobile units considering transport times and availability of waste in each location. Second, the amount to be processed at each site and period must be decided and, finally, the transport of the waste must be planned. A first version of this problem, which considers the direct transport of waste between two locations, was formulated mathematically by Alarcon-Gerbier and Buscher [62]. As mentioned by the authors, the problem becomes complex when solving medium to large-sized instances. Therefore, they also developed hybrid solution methods that combine metaheuristics with mathematical models, solving the problem in an iterative way. The authors subsequently presented a more extensive analysis of the problem studied, developing a new mathematical formulation that requires fewer integer variables at the expense of a larger number of constraints [63].

Figure 3 shows a sensitivity analysis similar to the one presented by Alarcon-Gerbier and Buscher [63]. In this case, however, the recycling network is composed of four MRUs and 30 nodes for a planning horizon of four periods (note that each node represents the location of a stakeholder involved in the planning). The base scenario considers a truck transport capacity of four tons, a storage capacity of 10 tons per site, and two trucks are required for the movement of one MRU. In addition, MRUs can be moved at the beginning of the four periods and we generated random instances using the same parameters as [63]. All our computational tests were performed on a $3.3 \mathrm{GHz}$ Intel Xeon CPU with $768 \mathrm{~GB}$ RAM, and the solution approaches were implemented in C\# programming language with Microsoft Visual Studio 2017 and Gurobi 9.0. As shown in Figure 3, increasing the transport capacity of trucks by $50 \%$ reduces the total transport distance by $27 \%$ and, thus, transport costs. Doubling the number of trucks required to move the MRUs has a negative impact on the objective function, increasing it by $23 \%$. In contrast, in the case where an MRU fits on one truck, a reduction of $18 \%$ is achieved. One parameter that has a major impact is the storage capacity at each site. Increasing storage capacity by $50 \%$ decreases total transport distances by $46 \%$. This is explained by the fact that considering large distributed storage capacities means that waste can be stored and processed without the need for transportation. Similarly, doubling the storage capacity decreases the target function by an additional $7 \%$. Finally, the mobility of the units considered implies that they can be 
moved at the beginning of each period. This allows better results to be achieved since the degrees of freedom are increased. However, this increases the complexity of the problem and may not be technically and economically viable. Therefore, we evaluated the impact of restricting the mobility of MRUs only at the beginning of the planning. This increases the objective function by $7 \%$. Similarly, allowing the movement of MRUs at the beginning of the first and third periods increases the total distances by $4 \%$ compared to the base scenario.

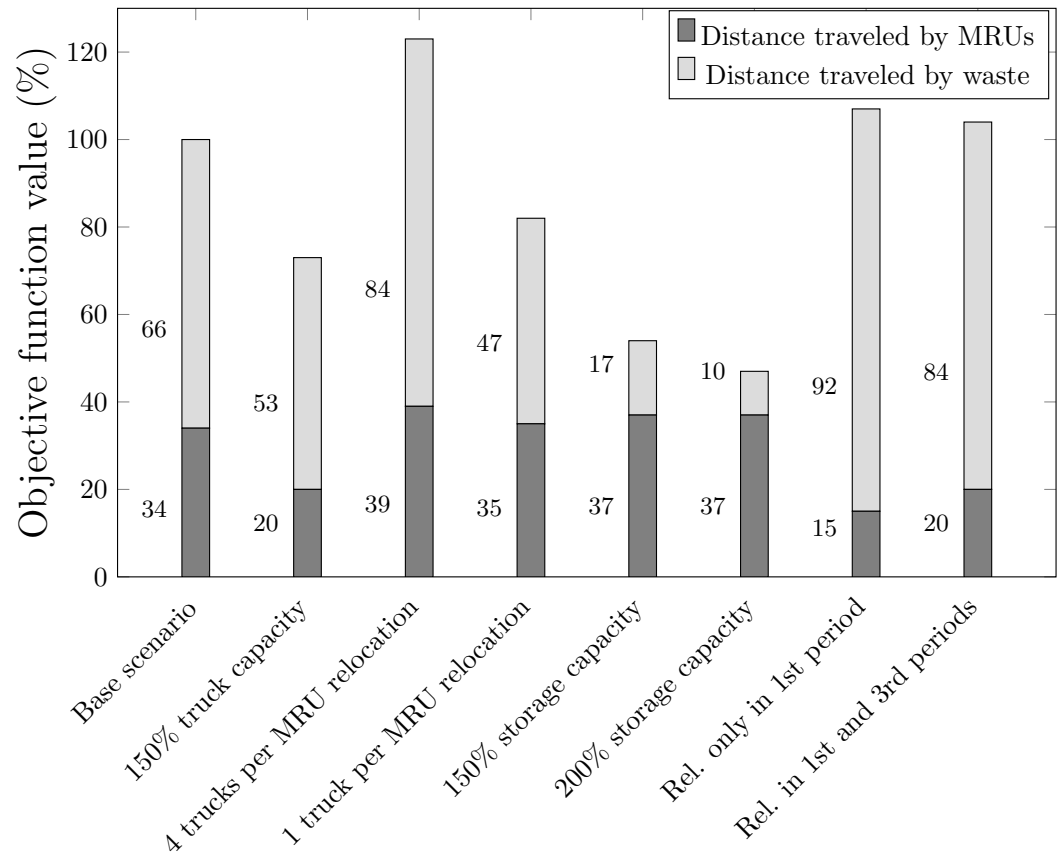

Figure 3. Sensitivity analysis for selected parameters.

We are currently focusing on a more detailed economic analysis of this problem. For this, we are looking to integrate the vehicle routing problem (VRP) associated with waste transport between sites. However, this further increases the complexity of the studied problem due to the extra complexity of this problem. The mathematical formulation integrating the location, production, and direct transport problem [62,63] can be expanded with relative ease by integrating the VRP. Note that we do not present this mathematical formulation as this would considerably extend the length of this paper. In addition, our primary focus is to show the effect of such integration compared to other solution approaches (for more details on integrated production and distribution formulations, see [64]).

Three solution approaches can be compared. First, it is interesting to evaluate the solution time required to solve the integrated approach (IA) as well as the objective function achieved. Second, a sequential approach (SA) is followed in which the location and production problem are first solved in an integrated manner, after which the transportation routes are determined. This would represent first solving the problem presented by AlarconGerbier and Buscher [62] and then solving the VRP based on the results of the previous planning. Finally, such an integrated problem could be solved periodically, which means that a multi-period problem composed of " $\mathrm{p}$ " periods is not solved, but " $\mathrm{p}$ " single-period problems are solved sequentially, which we call a rolling horizon approach (RHA). In this case, the solution of period " $\mathrm{p}$ " is integrated as parameters for the solution of period " $p+1$ ". The comparison of these three approaches is shown in Table 2. For the evaluation of the solution methods, we calculate the relative percentage difference (RPD). Here, we use the best solution obtained through the three methods being evaluated, labeled $Z_{\text {sol }}^{*}$, as 
the reference, and we compare it with the solution of each solution approach, labeled $Z_{\text {sol }}$, as shown in (1). In addition, we limited the calculation time to three hours.

$$
R P D=\frac{Z_{s o l}-Z_{s o l}^{*}}{Z_{s o l}}
$$

By comparing the three solution approaches, certain conclusions can be drawn. First, and considering two-period instances, it is observed that IA leads to the best results. The solutions obtained by SA differ by $8.3 \%$ and those by RHA by $5.6 \%$, demonstrating the benefits of integration. However, the calculation times confirm the complexity of IA. Of the four instances evaluated, only one was solved to optimality, with an average gap of $4.2 \%$ considering all four instances. In contrast, SA and RHA require considerably less time to find the best possible solution within the given conditions. The complexity of this problem can be further confirmed by looking at the four-period instances. Feasible solutions could only be found in three of them, with an average gap of $21.3 \%$. The other two approaches can be solved to optimality and deliver better results than IA. Based on these results, it can be stated that more sophisticated solution methods are required for the solution of this problem, which allow the obtaining of good results in short computational time.

Table 2. Comparison of different solution approaches.

\begin{tabular}{ccccccccc}
\hline \multirow{2}{*}{$\#$} & \multirow{2}{*}{ Periods } & \multicolumn{3}{c}{ IA } & \multicolumn{2}{c}{ SA } & \multicolumn{2}{c}{ RHA } \\
\cline { 3 - 9 } & & RPD (\%) & Gap & $\mathbf{T}_{C P U}$ & RPD (\%) & $\mathbf{T}_{C P U}$ & RPD (\%) & $\mathbf{T}_{C P U}$ \\
\hline 1 & 2 & 0.0 & 0.0 & 8369.0 & 12.3 & 0.7 & 4.1 & 83.8 \\
2 & 2 & 0.0 & 7.6 & $10,800.0$ & 7.5 & 0.6 & 6.5 & 1372.6 \\
3 & 2 & 0.0 & 4.7 & $10,800.0$ & 5.3 & 0.5 & 4.8 & 550.8 \\
4 & 2 & 0.0 & 4.2 & $10,800.0$ & 8.1 & 0.6 & 6.8 & 446.2 \\
\hline 5 & 4 & 11.5 & 23.8 & $10,800.0$ & 5.3 & 10.7 & 0.0 & 163.4 \\
6 & 4 & 0.0 & 17.2 & $10,800.0$ & 3.9 & 13.2 & 4.6 & 4388.5 \\
7 & 4 & 6.9 & 22.8 & $10,800.0$ & 4.4 & 9.5 & 0.0 & 749.3 \\
8 & 4 & - & - & $10,800.0$ & 5.7 & 33.7 & 0.0 & 474.4 \\
\hline
\end{tabular}

$\mathrm{T}_{C P U}$ : Run-time in seconds. Gap: MIP gap reported by Gurobi in \%.

\subsection{Control of Information Flows in SD-MSC}

For the control of SD-MSC components in the production network, a combination of material and information flows is required [65]. Quick adaptation of production conditions and task re-allocation requires a considerable improvement of control systems to correctly adjust unpredictability and disturbances in process dynamics [65]. An essential part of the network of production systems is an effective control and coordination of large compounds. Current manufacturing trends require an autonomous, intelligent, and coupled operation of inner systems [66]. Logic control, numerical control, or networked control could represent mechanisms for resource processing in machines [67]. Furthermore, a central programmable logic controller is used to efficiently distribute sensors and actuators amongst facilities and establish communication between them. In addition, dynamic networks could be managed by autonomous control, in which the information is transmitted between autonomous units in a decentralized manner [65]. It is crucial to define essential aspects for control in SD-MSC management, including an effective flow of production units and goods, security of information flow, and communication between multi-stakeholders.

Many corporations use cloud computing models or wireless networks in their infrastructure for the maintenance of their communication and their systems [68]. That creates various cause-and-effect dependencies in the security framework. The architecture vulnerabilities could threaten the security and privacy of the transferred data. Therefore, different data protection methods, such as encryption, firewalls, access control, and intrusion and leak detection systems, could be employed [68]. However, the main challenge of the datasecurity aspect is preserving control over the network and preventing external attacks on 
system components. Unable to prevent possible threats, intrusion detection systems play a significant role in securing the environment. They have the aim of detecting attacks and providing alerts for users. Thus, several technical issues are to be addressed to preserve the trustworthiness and reliability of security in the data-flow networks.

Integrating multiple processes and stakeholders increases the complexity due to the possible conflict between the objectives and operations of each participant. The design, materials, and components can come from different partners, making the controlling process more complex [38]. As the movable factory changes its locations in an SD-MSC, various internal (focal firm) and external (local) partners become involved. This may confront the communication and information flow necessary for effective integration with some problems. A key component for improving information exchange and communication between multiple stakeholders is building trust and commitment among them [49,50]. With a high level of supply chain trust, partners will establish an efficient collaboration and thereby increase the value-adding of any SD-MSC.

The efficient joint operation of multiple parties depends on the level of exchanged information and the degree of trustworthiness. Although a higher level of shared information results in a higher level of trust, it brings the risk of disclosing sensitive information [69]. Therefore, maintaining a balanced level of shared information, trust, and confidentiality is a vital challenge in controlling SD-MSCs. The relationship between entities to which the components belong should be established based on confidentiality agreements [70]. Therefore, the rules and regulations for data disclosure should be defined to optimally serve the overall system efficiency and minimize the harm caused by a lack of shared information. Since the quantity of information delivered during data exchange affects the utility of that data [71], the challenge of developing valid communication prescriptions remains in the information chain. On a technical level, there is a middle-ware layer or a trusted third party that enables information transfers inside the supply chain [72]. It provides the operation management, administering events and creating exceptions for the SD-MSC components. However, not all partners accept the inclusion of a trusted third-party in their strategic relationships.

\subsubsection{Case Study: Information Sharing in Production Industry}

In this section, we present results associated with information flows in the case study described in Section 3.2. For integration in SD-MSCs, companies $\mathrm{P}$ and $\mathrm{O}$ are obliged to share a certain amount of information on raw materials, operational conditions, and equipment functionality. Such a collaboration system needs a certain level of trust between companies $\mathrm{P}$ and $\mathrm{O}$. Essential information can be communicated quickly and efficiently owing to various developments in today's technologies. Sharing required information among partners helps to reduce the uncertainty and bullwhip effect within supply chain collaboration. However, due to the flexibility of relocation and multi-agent decision making over assets, exchanging information may be more difficult, resulting in less trust between companies $\mathrm{P}$ and $\mathrm{O}$. This problem was studied and analyzed by Ghondaghsaz and Engesser [51]. As mentioned by the authors, trust is the key to successful collaboration. However, building and maintaining trust in this case study is challenging. This study provides a conceptual model for combining strategies and outcomes of building trust. These strategies are continuous communication and information sharing, developing contracts and written agreements, promoting transparency and information clarity, long-term relationships and experience, selecting suitable partners, and mutual understandings of culture and language. Building and maintaining trust for the sharing of transparent information results in strategic collaboration and relationship investment. In addition, such collaboration in an SD-MSC requires confidentiality of the information being shared between partners. This could be achieved using various data anonymization and encryption techniques as well as careful selection and control of the shared extent of information. Privacy-preserving architecture for information exchange and use of homomorphic encryption in value chains was proposed by Chokparova and Urbas [73]. This research was based on investigations of previous 
implementations of additive homomorphic encryption techniques in different industries and the formulation of a confidentiality model applicable in MSCs.

\subsubsection{Simulation Based on Game Theory}

In this section, we present use of a game-theoretic [74] system model of the information sharing in production industries required to define involved players, their strategies, and relevant parameters that can affect their pay-offs. Payoffs are the quantified outcomes of the selected strategy in a game. Based on the strategies and their associated values, a pay-off matrix for the game between the players can be constructed.

In the case described in Section 3.2, the company $\mathrm{P}$ is a producer of an asset (manufacturing equipment or a process unit). This asset is shared to the company $\mathrm{O}$, which is an operator of this asset and gains some extent of control over the facility. Both parties need to provide a certain amount of information on the operation of the asset, which can be sensitive or contain sensitive parameters and data. For instance, company $\mathrm{P}$ can share the essential control variable and operating conditions for the production process with company $\mathrm{O}$. At the same time, company $\mathrm{P}$ is willing to collect statistical information on the operation over this asset, such as used time, generated outputs, and compositions. Therefore, some information flows between the partners are created.

Both partners can select a strategy for sharing sensitive knowledge, either a sharing or no-sharing strategy. This results in four combinations, as shown in Table 3.

Table 3. Game pay-off matrix.

\begin{tabular}{ccc}
\hline \multirow{2}{*}{ Producer } & \multicolumn{3}{c}{ Operator } \\
\cline { 2 - 3 } & Share & No-Share \\
\hline Share & $\left(R_{P 1}, R_{O 1}\right)$ & $\left(S_{P 2}, T_{O 2}\right)$ \\
No-share & $\left(T_{P 3}, S_{O 3}\right)$ & $\left(P_{P 4}, P_{O 4}\right)$ \\
\hline
\end{tabular}

In order to define the pay-off parameters of the matrix, parameters affecting information sharing in the SD-MSC relationship are included. The pay-off parameters [74-78] are as follows:

- $\quad I_{i}$ : Amount of sensitive information shared by the partner, where $i=P, O$

- $u_{i}$ : Utility of knowledge for $i=P, O$

- $\quad s$ : Stimulus coefficient when both partners are eager to share

- $T$ : Level of trust between partners

- $\quad V_{i}$ : Value of sensitive process knowledge sharing provided by $i=P, O$

- $\quad p$ : Penalty coefficient for non-sharing

The pay-offs $\Pi_{i}$ of the partners within an evolutionary game model are defined for share $(S)$ and no-share $(N)$ strategies [74]. The probabilities of taking a share strategy by company $\mathrm{P}$ and company $\mathrm{O}$ are denoted by $x$ and $y$, respectively [79]. The reward for choosing a share strategy is denoted by $R_{i}$, the pay-off $S_{i}$ is computed when a cooperator is affected by the temptation to defect $T_{i}$, and punishment $P_{i}$ is received in case of a mutual defect [80]. The full game model is defined by groups of Equations (2) and (3).

$$
\begin{aligned}
& \Pi_{P}^{S}=y \cdot R_{P 1}+(1-y) \cdot S_{P 2} \\
& \Pi_{P}^{N}=y \cdot T_{P 3}+(1-y) \cdot P_{P 4} \\
& R_{P 1}=s \cdot I_{P}+u_{P} \cdot T \cdot I_{O}-V_{P} \\
& S_{P 2}=-V_{P} \\
& T_{P 3}=\left(u_{P}-p\right) \cdot I_{O} \\
& P_{P 4}=0
\end{aligned}
$$

$$
\begin{aligned}
& \Pi_{O}^{S}=x \cdot R_{O 1}+(1-x) \cdot T_{O 2} \\
& \Pi_{O}^{N}=x \cdot S_{O 3}+(1-x) \cdot P_{O 4} \\
& R_{O 1}=s \cdot I_{O}+u_{O} \cdot T \cdot I_{P}-V_{O} \\
& T_{O 2}=\left(u_{O}-p\right) \cdot I_{P} \\
& S_{O 3}=-V_{O} \\
& P_{O 4}=0
\end{aligned}
$$


In order to simulate the dynamics of the game [81], replicator dynamics Equation (4) are used. This approach allows for an investigation of the effects of trust level on the probabilities of accepting the share strategy.

$$
\begin{aligned}
& x^{\prime}=x \cdot(1-x) \cdot\left[y \cdot R_{P 1}+(1-y) \cdot S_{P 2}-y \cdot T_{P 3}-(1-y) \cdot P_{P 4}\right] \\
& y^{\prime}=y \cdot(1-y) \cdot\left[x \cdot v \cdot R_{O 1}-x \cdot T_{O 2}+(1-x) \cdot S_{O 3}-(1-x) \cdot P_{O 4}\right]
\end{aligned}
$$

The solution of differential equations was conducted for companies $\mathrm{P}$ and $\mathrm{O}$ with different initial conditions: $x, y=[0.10,0.25,0.50,0.75,0.99]$. The parameters for calculation of pay-offs were chosen randomly with a certain extent of logic characterizing the information sharing system between $P$ and $O$. However, selected values of the parameters were not changed throughout the study in order to observe a true system dynamic at a specific set of parameters.

An investigation of the impact of trust between parties on the probability of the choosing by them the share strategy was conducted by varying the trust level. The observation of Figure 4 shows that the producer is not willing to share sensitive information at low levels of trust, whereas at trust levels higher than 0.5 , the party is more willing to adopt this strategy.
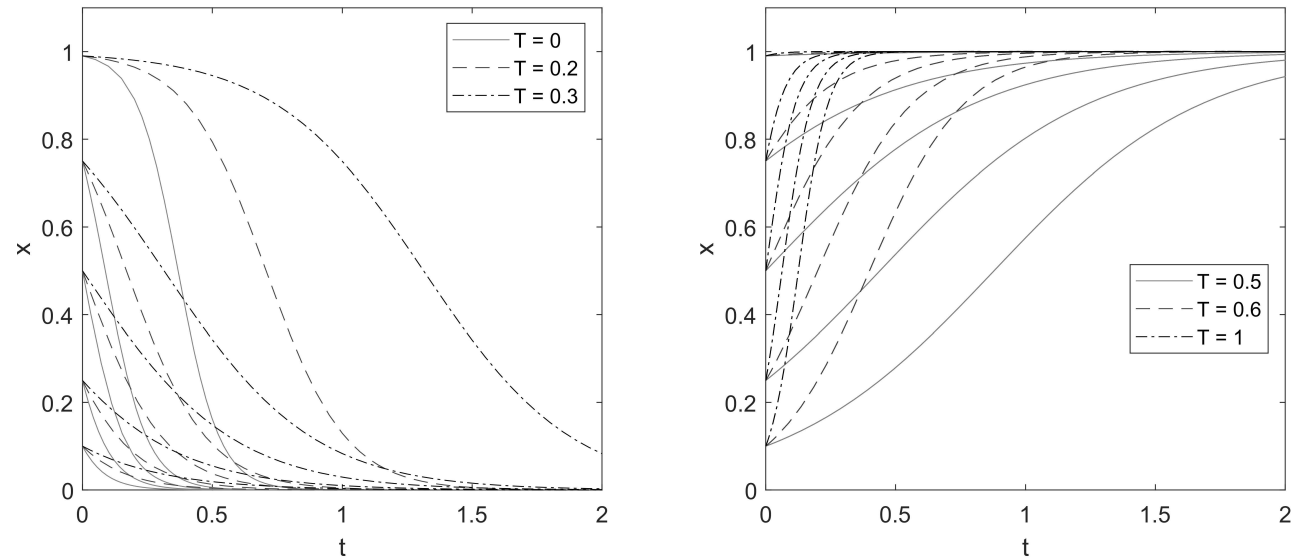

Figure 4. Probability of knowledge sharing by the producer at various trust levels.

According to Figure 5, a similar behavior could be observed from the side of the operator. The probability of adopting no-share strategy raises with the decrease in trust between partners.
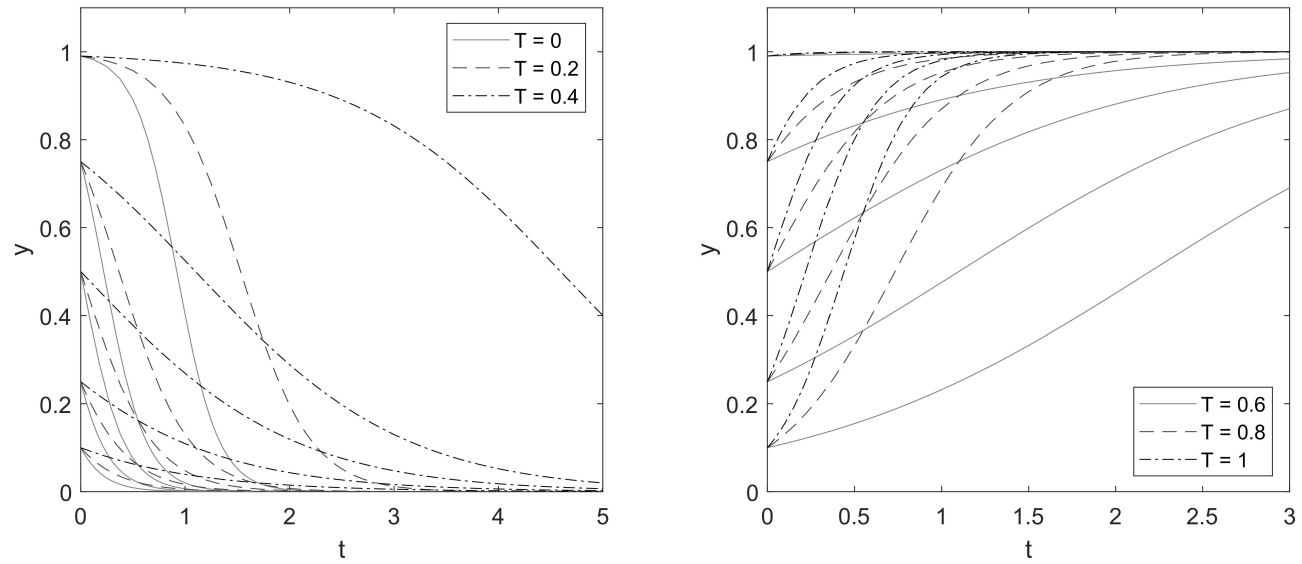

Figure 5. Probability of knowledge sharing by the operator at various trust levels.

Comparison of Figures 4 and 5 suggests that a longer time is needed for the operator to adopt a share strategy compared to the producer in a simulation with the same pay-off matrix parameters. 
This analysis allowed for the investigation of trust effects on the knowledge sharing decisions regarding sensitive information within the investigated producer-operator system. It was identified that a higher level of trust in the relationship is required for information sharing in SD-MSCs. This shows that partners are not eager to share sensitive information in the early stages of their relationships. However, as they gain experience with their partners and maintain trust in their relationship when implementing SD-MSCs, their willingness to share sensitive information increases. This result is consistent with previous studies which show trust is a key for efficiently sharing information amongst partners in complex ecosystems [82-84]. Nevertheless, a more thorough analysis is required to account for more parameters which may impact a collaborative interaction.

Another limitation of this study is that further investigations of strategy selection are required for outcomes with a collaborator that is reluctant to share the information necessary for the operation of the assets. In this case, instead of a no-share strategy, a confidential information transfer could be suggested. This is achievable through various encryption methods [85], secure multiparty computation [86], or other information privacypreserving techniques [87]. As a result, the information value and information sensitivity parameters of the encoded or protected data can be expanded, and their effects on the operation of the SD-MSC can be analyzed further.

\section{Managerial Insights}

This study contributes in several ways to the practical and managerial field. The current paper defines and evaluates the concept of SD-MSCs, in which production tasks can be replicated and repeated at several locations and smaller scales. Advanced technologies and highly competitive markets have forced firms to seek out innovative strategic plans to maintain or even increase their market share. Therefore, this study presents advisable options for firm managers to understand a new and innovative concept gaining popularity in several industries and developed regions. Furthermore, this study outlines a path for firms to comprehend the challenges and requirements, controlling approaches, and practical business models for implementing an SD-MSC. Through the proposed case studies, managers will learn about real-world applications of SD-MSCs and be better prepared for challenges and solutions in the real world. We recommend that they consider these case studies as prototypes before investing in an SD-MSC. Particularly, due to the mobility of the modular units, the assumption that production sites are immobile no longer applies. Therefore, we recommend that industrial managers consider the location decision at the tactical/operational level rather than the strategic level, and to be made together with the short-term planning of production and distribution. However, the optimization of such problems in an integrated manner brings a high level of complexity. Therefore, new solution approaches should be developed for this novel type of simultaneous planning in which multiple stakeholders are also involved. Finally, this study provides insights for managers regarding communication and information systems in SD-MSCs. Previous studies related to decentralized manufacturing have focused on this area less. Information systems ensure the correct operation of modular equipment installed in a decentralized manner. The system should detect, process, and send information between different stakeholders or production assets, allowing for effective information exchange and communication. As trust is vital for efficient and transparent communication and collaboration among partners in the supply chain, we recommend that the managers pay considerable attention to building and maintaining trust when implementing an SD-MSC. In scenarios that partners collaborate in a trusting relationship, the willingness to share a higher level of information emerges. However, this may cause challenges regarding information security. In this case, some partners may refuse to share information due to confidentiality concerns. Therefore, managers need to be aware of this tension between trust and confidentiality, and they need to apply data security approaches mentioned in this paper to balance the tension between trust and confidentiality. 


\section{Conclusions}

In this paper, we conducted a characterization of SD-MSCs. This concept is based on the idea that modular facilities can be easily relocated and even shared among different stakeholders to manufacture products in a decentralized manner. This flexibility in terms of mobility is achieved mainly through the modularization of production capacity, which allows them to be moved from one place to another at low cost and at short notice. The correct operation and implementation of such a production network requires a correct interconnection and information flow that can be ensured through the use of appropriate information systems.

We defined two types of business models that can arise with the mobility of productive units. On the one hand, Infrastructure-as-a-Service is associated with the installation of modular units for decentralized production, meaning that a company can install its production capacity at the customer's site, supplier's site, or at sites that can be rented for the installation of modular units. On the other hand, Module-as-a-Service means that companies without (sufficient) capacity may choose to lease or rent modular units for the manufacture of new products or to meet peaks in demand that exceed available capacity. In all these cases, agreements between different stakeholders are required, accompanied by information systems that allow a rapid control and flow of information. In addition, we presented two case studies in which these business opportunities can be applied. In order to promote decentralized recycling, the implementation of a recycling network composed of modular units was evaluated. These can be moved according to the amount of waste at each collection point in order to minimize distances and transportation costs. The second case focuses on the opportunity to share assets among different companies for decentralized manufacturing in the process industries sector.

Different aspects of control, communication, trust in partnership, and confidentiality in information systems have been discussed in this line of research. However, there is a need for detailed and empirical studies to investigate these facets in SD-MSCs. Therefore, we encourage future research to focus on the role of information quality and information sharing on the level of trust in SD-MSCs. There is a necessity to balance the amount of information the partners are willing to communicate with each other and the cost of disclosure-associated risks for the partners. Information disclosure contributes to the agility, adaptability, and flexibility of SD-MCS, whereas the risks of preserving confidentiality are tightly related to trust in the relationship and might affect the quality of the shared information. Solving this conflict implies considering various techniques for the secure computation of information shared in anonymized or encrypted forms. Subsequent research and implementation of such solutions in this direction would facilitate the closure of the integration loop between SD-MSCs. In addition, the consideration of the mobility of the production capacity in planning leads to new optimization problems which have yet to be studied in detail in the literature. Therefore, future research should focus on the development of solution methods capable of obtaining (near) optimal solutions in adequate computational time. Similarly, it should also be studied under which conditions mobile production units prove to be particularly advantageous, and to what extent the mobility of production facilities influences the physical transport of goods, which may depend on the manufactured products, the raw material needed, or on the specific business model of each company. Finally, an SD-MSC is influenced by several stakeholders in relationships regulated by supply contracts. Here, a single production planning cannot easily be realized since each participant may have conflicting objectives. Therefore, optimization models in the area of multiple criteria decision making should be investigated in order to find optimal planning solutions, taking into account the presence of trade-offs between several conflicting objectives. 
Author Contributions: Conceptualization, E.A.-G., Z.C., N.G., W.Z., H.S.-M. and U.A.; methodology, E.A.-G., Z.C., N.G., W.Z. and U.A.; validation, E.A.-G., Z.C., N.G. and W.Z.; formal analysis, E.A.-G., Z.C., N.G., W.Z., H.S.-M. and U.A.; investigation, E.A.-G., Z.C., N.G., W.Z., H.S.-M., U.A. and O.O.; Writing-Original draft preparation, E.A.-G., Z.C., N.G., W.Z., H.S.-M., U.A. and O.O.; WritingReview and editing, E.A.-G., Z.C., N.G. and W.Z.; visualization, E.A.-G. and Z.C.; supervision, U.A. All authors have read and agreed to the published version of the manuscript.

Funding: The authors wish to thank the Friedrich and Elisabeth Boysen Foundation and Technische Universität Dresden for their financial support for this work during the third Boysen-TU Dresden Research Training Group. In addition, the last author wishes to thank the German Research Foundation (DFG) for the financial support at the Research Training Group Role-Based Software Infrastructures for Continuous-Context-Sensitive Systems.

Institutional Review Board Statement: Not applicable.

Informed Consent Statement: Not applicable.

Data Availability Statement: Not applicable.

Acknowledgments: The authors would like to thank their scientific advisors U. Buscher, L. Urbas, S. Engesser, and J. Schönberger for their continuous support. In addition, the authors also thank the anonymous reviewers for their valuable and detailed comments that helped to significantly improve the quality of this work.

Conflicts of Interest: The authors declare no conflict of interest.

\section{References}

1. Rauch, E.; Dallasega, P.; Matt, D.T. Distributed manufacturing network models of smart and agile mini-factories. Int. J. Agil. Syst. Manag. 2017, 10, 185-250. [CrossRef]

2. WEF. Technology and Innovation for the Future of Production: Accelerating Value Creation; White Paper; World Economic Forum: Geneva, Switzerland, 2017.

3. Schlemmer. Mobile Factory: Flexibility at the Touch of a Button. 2020. Available online: https://www.schlemmer.com/ (accessed on 4 March 2021).

4. Mobile Smart Factory. Optimizing Spare Parts Management Using Mobile 3D Printing Solutions; White Paper; Bionic Production GmbH: Lunenburg, Germany, 2020.

5. Pfizer. Pfizer Announces Collaboration with GSK on Next-Generation Design of Portable, Continuous, Miniature and Modular (PCMM) Oral Solid Dose Development and Manufacturing Units. 2015. Available online: https://www.pfizer.com (accessed on 2 February 2021).

6. Unilever. How Our Engineers Fitted a Factory into a 40-Foot Container. 2021. Available online: https://www.unilever.com/ (accessed on 25 February 2021).

7. Biofabrik. Decentralized Plastic Recycling. 2018. Available online: https://biofabrik.com (accessed on 3 April 2021).

8. Dynamis Energy. Portable Solid Waste Destruction. 2015. Available online: https://www.dynamisenergy.com/ (accessed on 10 April 2021).

9. Pyrotech Energy. Mobile Pyrolysis Plant. 2020. Available online: https://pyrotechenergy.com/ (accessed on 10 April 2021).

10. ZVEI. Process Industrie 4.0: The Age of Modular Production-On the Doorstep to Market Launch; Technical Report; Zentralverband Elektrotechnik- und Elektronikindustrie e.V.: Frankfurt am Main, Germany, 2019.

11. Palys, M.J.; Allman, A.; Daoutidis, P. Exploring the Benefits of Modular Renewable-Powered Ammonia Production: A Supply Chain Optimization Study. Ind. Eng. Chem. Res. 2018, 58, 5898-5908. [CrossRef]

12. Bhosekar, A.; Ierapetritou, M. A framework for supply chain optimization for modular manufacturing with production feasibility analysis. Comput. Chem. Eng. 2021, 145, 107175. [CrossRef]

13. Shao, Y.; Hu, Y.; Zavala, V.M. Mitigating investment risk using modular technologies. Comput. Chem. Eng. 2021, $153,107424$. [CrossRef]

14. Allman, A.; Zhang, Q. Dynamic location of modular manufacturing facilities with relocation of individual modules. Eur. J. Oper. Res. 2020, 286, 494-507. [CrossRef]

15. Becker, T.; Lier, S.; Werners, B. Value of modular production concepts in future chemical industry production networks. Eur. J. Oper. Res. 2019, 276, 957-970. [CrossRef]

16. Güden, H.; Süral, H. Locating mobile facilities in railway construction management. Omega 2014, 45, 71-79. [CrossRef]

17. Gao, J.; You, F. Can Modular Manufacturing Be the Next Game-Changer in Shale Gas Supply Chain Design and Operations for Economic and Environmental Sustainability? ACS Sustain. Chem. Eng. 2017, 5, 10046-10071. [CrossRef]

18. Tan, S.H.; Barton, P.I. Optimal dynamic allocation of mobile plants to monetize associated or stranded natural gas, part I: Bakken shale play case study. Energy 2015, 93, 1581-1594. [CrossRef] 
19. Aßmann, U.; Buscher, U.; Engesser, S.; Schönberger, J.; Urbas, L. Software-Defined Mobile Supply Chains. In Dynamics in Logistics; Springer: Cham, Switzerland, 2020; pp. 420-430. [CrossRef]

20. Khajavi, S.H.; Partanen, J.; Holmström, J. Additive manufacturing in the spare parts supply chain. Comput. Ind. 2014, 65, 50-63. [CrossRef]

21. Liu, J.; Liu, Z. A Survey on Security Verification of Blockchain Smart Contracts. IEEE Access 2019, 7, 77894-77904. [CrossRef]

22. Rao, S.K.; Prasad, R. Impact of 5G Technologies on Industry 4.0. Wirel. Pers. Commun. 2018, 100, 145-159. [CrossRef]

23. Wan, J.; Tang, S.; Shu, Z.; Li, D.; Wang, S.; Imran, M.; Vasilakos, A. Software-Defined Industrial Internet of Things in the Context of Industry 4.0. IEEE Sen. J. 2016, 16, 7373-7380. [CrossRef]

24. Uhlemann, T.H.J.; Lehmann, C.; Steinhilper, R. The digital twin: Realizing the cyber-physical production system for Industry 4.0. Procedia CIRP 2017, 61, 335-340. [CrossRef]

25. Mourtzis, D.; Doukas, M. Decentralized manufacturing systems review: Challenges and outlook. Logist. Res. $2012,5,113-121$. [CrossRef]

26. Mourtzis, D.; Doukas, M.; Psarommatis, F. A multi-criteria evaluation of centralized and decentralized production networks in a highly customer-driven environment. CIRP Ann. 2012, 61, 427-430. [CrossRef]

27. Srai, J.S.; Kumar, M.; Graham, G.; Phillips, W.; Tooze, J.; Ford, S.; Beecher, P.; Raj, B.; Gregory, M.; Tiwari, M.K.; et al. Distributed manufacturing: Scope, challenges and opportunities. Int. J. Prod. Res. 2016, 54, 6917-6935. [CrossRef]

28. Rauch, E.; Dallasega, P.; Matt, D.T. Sustainable production in emerging markets through Distributed Manufacturing Systems (DMS). J. Clean. Prod. 2016, 135, 127-138. [CrossRef]

29. Barni, A.; Corti, D.; Pedrazzoli, P.; Rovere, D.; Lucisano, G. Mini-factories for Close-to-customer Manufacturing of Customized Furniture: From Concept to Real Demo. Procedia Manuf. 2017, 11, 854-862. [CrossRef]

30. Reichwald, R.; Stotko, C.M.; Piller, F.T. Distributed mini-factory networks as a form of real-time enterprise: Concept, flexibility potential and case studies. In The Practical Real-Time Enterprise; Springer: Berlin/Heidelberg, Germany, 2005; pp. 403-434. [CrossRef]

31. Mehrabi, M.G.; Ulsoy, A.G.; Koren, Y. Reconfigurable manufacturing systems: Key to future manufacturing. J. Intell. Manuf. 2000, 11, 403-419. [CrossRef]

32. ElMaraghy, H.A. Flexible and reconfigurable manufacturing systems paradigms. Int. J. Flex. Manuf. Syst. 2005, 17, 261-276. [CrossRef]

33. Bi, Z.M.; Lang, S.Y.T.; Shen, W.; Wang, L. Reconfigurable manufacturing systems: The state of the art. Int. J. Prod. Res. 2008, 46, 967-992. [CrossRef]

34. Koren, Y.; Gu, X.; Guo, W. Reconfigurable manufacturing systems: Principles, design, and future trends. Front. Mech. Eng. 2018, 13, 121-136. [CrossRef]

35. Stillström, C.; Jackson, M. The concept of mobile manufacturing. J. Manuf. Syst. 2007, 26, 188-193. [CrossRef]

36. Lier, S.; Wörsdörfer, D.; Grünewald, M. Transformable Production Concepts: Flexible, Mobile, Decentralized, Modular, Fast. ChemBioEng Rev. 2016, 3, 16-25. [CrossRef]

37. Jackson, M.; Wiktorsson, M.; Bellgran, M. Factory-in-a-box-Demonstrating the next generation manufacturing provider. In Manufacturing Systems and Technologies for the New Frontier; Springer: London, UK, 2008; pp. 341-346. [CrossRef]

38. Peltokoski, M.; Volotinen, J.; Lohtander, M. Location Independent Manufacturing-A Software Solution for Supply Chains. Procedia Manuf. 2017, 11, 863-870. [CrossRef]

39. Fox, S. Moveable factories: How to enable sustainable widespread manufacturing by local people in regions without manufacturing skills and infrastructure. Technol. Soc. 2015, 42, 49-60. [CrossRef]

40. Fox, S. Moveable Production Systems for Sustainable Development and Trade: Limitations, Opportunities and Barriers. Sustainability 2019, 11, 5154. [CrossRef]

41. Jiang, Z.; Wang, H.; Tian, Q.; Guo, W. Co-Design of Supply Chain Network and Subassembly Planning Considering the Reconfiguration of Supply Chain Structure for Factory-in-a-Box Manufacturing. In Proceedings of the ASME 2018 13th International Manufacturing Science and Engineering Conference, College Station, TX, USA, 18-22 June 2018. [CrossRef]

42. Pasha, J.; Dulebenets, M.A.; Kavoosi, M.; Abioye, O.F.; Wang, H.; Guo, W. An Optimization Model and Solution Algorithms for the Vehicle Routing Problem With a "Factory-in-a-Box". IEEE Access 2020, 8, 134743-134763. [CrossRef]

43. Adamietz, R.; Giesen, T.; Mayer, P.; Johnson, A.; Bibb, R.; Seifarth, C. Reconfigurable and transportable container-integrated production system. Robot. Comput.-Integr. Manuf. 2018, 53, 1-20. [CrossRef]

44. Alix, T.; Benama, Y.; Perry, N. A framework for the design of a Reconfigurable and Mobile Manufacturing System. Procedia Manuf. 2019, 35, 304-309. [CrossRef]

45. Rauch, E.; Matt, D.T.; Dallasega, P. Mobile On-site Factories-Scalable and distributed manufacturing systems for the construction industry. In Proceedings of the 2015 International Conference on Industrial Engineering and Operations Management (IEOM), Dubai, United Arab Emirates, 3-5 March 2015. [CrossRef]

46. Rauch, E.; Matt, D.T.; Dallasega, P. Mobile Factory Network (MFN)—Network of Flexible and Agile Manufacturing Systems in the Construction Industry. Appl. Mech. Mater. 2015, 752-753, 1368-1373. [CrossRef]

47. Eng, T.Y. Mobile supply chain management: Challenges for implementation. Technovation 2006, 26, 682-686. [CrossRef]

48. MIT News. Pharmacy on Demand. New, Portable System Can Be Configured to Produce Different Drugs. 2016. Available online: https:// news.mit.edu/ (accessed on 3 March 2021). 
49. Kwon, I.W.G.; Suh, T. Factors Affecting the Level of Trust and Commitment in Supply Chain Relationships. J. Supply Chain. Manag. 2004, 40, 4-14. [CrossRef]

50. Wiengarten, F.; Humphreys, P.; Cao, G.; Fynes, B.; McKittrick, A. Collaborative supply chain practices and performance: Exploring the key role of information quality. Supply Chain. Manag. Int. J. 2010, 15, 463-473. [CrossRef]

51. Ghondaghsaz, N.; Engesser, S. Identification of factors and outcomes of trust in mobile supply chains. Eur. J. Manag. Bus. Econ. 2021, ahead-of-print. [CrossRef]

52. Kerschbaum, F.; Schröpfer, A.; Zilli, A.; Pibernik, R.; Catrina, O.; de Hoog, S.; Schoenmakers, B.; Cimato, S.; Damiani, E. Secure Collaborative Supply-Chain Management. IEEE Comput. Soc. 2011, 44, 38-43. [CrossRef]

53. Chatterjee, A.; Mi Aung, K.M. Fully Homomorphic Encryption in Real World Applications; Springer: Singapore, 2019. [CrossRef]

54. Bretzke, W.R. Logistische Netzwerke; Springer: Berlin/Heidelberg, Germany, 2010. [CrossRef]

55. Arabani, A.B.; Farahani, R.Z. Facility location dynamics: An overview of classifications and applications. Comput. Ind. Eng. 2012, 62, 408-420. [CrossRef]

56. Shahmoradi-Moghadam, H.; Schönberger, J. Coordinated allocation production routing problem for mobile supply chains with shared factories. Comput. Chem. Eng. 2021, 155, 107501. [CrossRef]

57. Braekers, K.; Ramaekers, K.; Nieuwenhuyse, I.V. The vehicle routing problem: State of the art classification and review. Comput. Ind. Eng. 2016, 99, 300-313. [CrossRef]

58. Nagy, G.; Salhi, S. Location-routing: Issues, models and methods. Eur. J. Oper. Res. 2007, 177, 649-672. [CrossRef]

59. Chen, Z.L. Integrated Production and Distribution Operations: Taxonomy, Models and Review. In Handbook of Quantitative Supply Chain Analysis; Springer: Boston, MA, USA, 2004; Volume 74, pp. 711-745. [CrossRef]

60. Alarcon-Gerbier, E. Facility Location with Modular Capacities for Distributed Scheduling Problems. In Operations Research Proceedings; Springer: Cham, Switzerland, 2020; pp. 545-551. [CrossRef]

61. Alarcon-Gerbier, E.; Buscher, U. Integrated Scheduling of Production and Distribution Operations with Site Selection. In Logistics Management; Springer: Cham, Switzerland, 2019; pp. 255-267. [CrossRef]

62. Alarcon-Gerbier, E.; Buscher, U. Minimizing Movements in Location Problems with Mobile Recycling Units. In Lecture Notes in Computer Science; Springer: Cham, Switzerland, 2020; pp. 396-411. [CrossRef]

63. Alarcon-Gerbier, E.; Buscher, U. Solving the Dynamic Location-Inventory Problem for Mobile Recycling Units with Matheuristics. Ann. Oper. Res. 2021. submitted.

64. Adulyasak, Y.; Cordeau, J.F.; Jans, R. The production routing problem: A review of formulations and solution algorithms. Comput. Oper. Res. 2015, 55, 141-152. [CrossRef]

65. Armbruster, D.; De Beer, C.; Freitag, M.; Jagalski, T.; Ringhofer, C. Autonomous control of production networks using a pheromone approach. Phys. Stat. Mech. Appl. 2006, 363, 104-114. [CrossRef]

66. Lee, S.M.; Harrison, R.; West, A.A. A component-based distributed control system for assembly automation. In Proceedings of the 2nd IEEE International Conference on Industrial Informatics, INDIN’04 2004, Berlin, Germany, 24-26 June 2004; pp. 33-38. [CrossRef]

67. Appel, M.W.; Walther, M.; Konigorski, U. Modeling and Control of Production Networks. In Proceedings of the 2018 25th International Conference on Mechatronics and Machine Vision in Practice, M2VIP 2018, Stuttgart, Germany, 20-22 November 2018; pp. 1-6. [CrossRef]

68. Tan, Z.; Nagar, U.T.; He, X.; Nanda, P.; Liu, R.P.; Wang, S.; Hu, J. Enhancing big data security with collaborative intrusion detection. IEEE Cloud Comput. 2014, 1, 27-33. [CrossRef]

69. Bertino, E.; Khan, L.; Sandhu, R.; Thuraisingham, B. Secure knowledge management: Confidentiality, trust, and privacy. IEEE Trans. Syst. Man Cybern.-Part A Syst. Hum. 2006, 36, 429-438. [CrossRef]

70. Handfield, R.B.; Bechtel, C. The role of trust and relationship structure in improving supply chain responsiveness. Ind. Mark. Manag. 2002, 31, 367-382. [CrossRef]

71. Duncan, G.T.; Stokes, S.L. Disclosure Risk vs. Data Utility: The R-U Confidentiality Map as Applied to Topcoding. Chance 2004, 17, 16-20. [CrossRef]

72. Delia, M.; Cristi, V. Using Web Technologies for Supply Chain Management. In Supply Chain Management-Pathways for Research and Practice; IntechOpen: London, UK, 2011. [CrossRef]

73. Chokparova, Z.; Urbas, L. Utilization of Homomorphic Cryptosystems for Information Exchange in Value Chains. In Proceedings of the 2021 26th IEEE International Conference on Emerging Technologies and Factory Automation, Vasteras, Sweden, 7-10 September 2021. [CrossRef]

74. Hao, C.; Du, Q.; Huang, Y.; Shao, L.; Yan, Y. Evolutionary Game Analysis on Knowledge-Sharing Behavior in the Construction Supply Chain. Sustainability 2019, 11, 5319. [CrossRef]

75. Ding, X.H.; Huang, R.H. Effects of knowledge spillover on inter-organizational resource sharing decision in collaborative knowledge creation. Eur. J. Oper. Res. 2010, 201, 949-959. [CrossRef]

76. Cai, G.; Kock, N. An evolutionary game theoretic perspective on e-collaboration: The collaboration effort and media relativeness. Eur. J. Oper. Res. 2009, 194, 821-833. [CrossRef]

77. Arsenyan, J.; Büyüközkan, G.; Feyzioğlu, O. Modeling collaboration formation with a game theory approach. Expert Syst. Appl. 2015, 42, 2073-2085. [CrossRef] 
78. Mohebbi, S.; Li, X. Coalitional game theory approach to modeling suppliers' collaboration in supply networks. Int. J. Prod. Econ. 2015, 169, 333-342. [CrossRef]

79. Ruan, G.; Ruan, P. Knowledge sharing within innovation network members with Netlogo simulation platform. In Proceedings of the 2011 International Conference of Information Technology, Computer Engineering and Management Sciences, ICM 2011, Nanjing, China, 24-25 September 2011; Volume 2, pp. 210-213. [CrossRef]

80. García, J.; van Veelen, M. No strategy can win in the repeated prisoner's dilemma: Linking game theory and computer simulations. Front. Robot. AI 2018, 5, 102. [CrossRef]

81. Roca, C.P.; Cuesta, J.A.; Sánchez, A. Evolutionary game theory: Temporal and spatial effects beyond replicator dynamics. Phys. Life Rev. 2009, 6, 208-249. [CrossRef] [PubMed]

82. Ghosh, A.; Fedorowicz, J. The role of trust in supply chain governance. Bus. Process. Manag. J. 2008, 14, 453-470. [CrossRef]

83. Ebrahim-Khanjari, N.; Hopp, W.; Iravani, S.M.R. Trust and Information Sharing in Supply Chains. Prod. Oper. Manag. 2012, 21, 444-464. [CrossRef]

84. Pooe, D.; Mafini, C.; Loury-Okoumba, V.W. The influence of information sharing, supplier trust and supplier synergy on supplier performance: The case of small and medium enterprises. J. Transp. Supply Chain. Manag. 2015, 9, a187. [CrossRef]

85. Kogiso, K. Encrypted control using multiplicative homomorphic encryption. In Privacy in Dynamical Systems; Springer: Cham, Switzerland, 2019; pp. 267-286. [CrossRef]

86. Zhao, C.; Zhao, S.; Zhao, M.; Chen, Z.; Gao, C.Z.; Li, H.; Tan, Y.A. Secure Multi-Party Computation: Theory, practice and applications. Inf. Sci. 2019, 476, 357-372. [CrossRef]

87. Zheng, X.; Cai, Z. Privacy-Preserved Data Sharing towards Multiple Parties in Industrial IoTs. IEEE J. Sel. Areas Commun. 2020, 38, 968-979. [CrossRef] 